\title{
Tertúlia literária: construindo caminhos para a formação literária de professores alfabetizadores na universidade
}

\author{
Celia Abicalil Belmiro* \\ Maria Zélia Versiani Machado** \\ Mônica Correia Baptista***
}

\section{Resumo}

Este artigo apresenta reflexóes sobre a formação literária de professores de escolas públicas que atuam na educação infantil e nos anos iniciais do ensino fundamental, na condição de participantes de um projeto de extensão da Universidade Federal de Minas Gerais. Iniciado no ano de 2009, o projeto Tertúlia Literária: quem lêe também tem muito a dizer concebe a prática da leitura como uma atividade propícia ao estabelecimento de relaçóes intersubjetivas, e, para que isso ocorra, promove encontros mensais com o objetivo de socialização de leituras realizadas a cada mês por professores e mediadores convidados. Em seis anos ininterruptos de encontros e atividades diversas, mantém-se a finalidade de destacar a literatura como uma das leituras que devem fazer parte da vida e, consequentemente, da trajetória de formação dos professores. A experiência acumulada reúne elementos sobre a leitura literária no contexto do Projeto, que busca romper com modelos de formação que dificultam e até mesmo afastam o almejado encontro dos leitores com os livros de literatura. Este texto se propóe a discutir e problematizar aspectos relativos à leitura literária que o Projeto tem revelado, em contexto de formação na Universidade.

Palavras-chave: Literatura. Leitura literária. Formação docente.

\footnotetext{
* Doutora em Educação pela Universidade Federal de Fluminense (UFF). Professora da Faculdade de Educação da Universidade Federal de Minas Gerais (UFMG).

** Doutora em Educação pela Universidade Federal de Minas Gerais (UFMG). Professora do Departamento de Métodos e Técnicas de Ensino e do Programa de Pós-Graduaçáo da Faculdade de Educação da Universidade Federal de Minas Gerais (UFMG).

*** Doutora em Educaçáo pela Universidade Autônoma de Barcelona. Professora da Faculdade de Educação Universidade Federal de Minas Gerais (UFMG).
} 


\section{A leitura literária e a formação de professores}

A crescente preocupação em abordar os usos e funçóes sociais que a língua escrita adquire nos diferentes contextos sociais, durante os processos de escolarização, em especial naqueles em que as crianças iniciam seu contato com a linguagem escrita, vem chamando a atenção de pesquisadores. Atrelada a esta preocupação, ganha destaque a relação que o professor estabelece com a leitura e a escrita na sua vida cotidiana e a maneira como os cursos de formação lidam com essa questão. Observa-se que, em muitos casos, os professores, nos seus cursos de formação, tanto inicial quanto continuada, aprendem a ensinar leitura e escrita sem que, muitas vezes, tornem-se eles mesmos leitores e produtores de textos. Como assinalou Kramer (2002), de uma maneira geral, os futuros docentes copiam, fazem resumos, reproduzem textos e muito menos frequentemente vivenciam situações que estimulam a autoria e a fruição. $\mathrm{Na}$ sala de aula, o professor costuma reproduzir, nas práticas que desenvolve com seus alunos, a mesma concepção instrumental em relaçáo à linguagem escrita. Constata-se, em suma, que os professores, quer na sua formação inicial, quer, mais tarde, na sua ação profissional, nem sempre são estimulados a fazer uso da leitura e da escrita como atividades que implicam um movimento intelectual mais desafiador.

Essa concepção instrumental da língua repercute, evidentemente, no ensino da literatura, muitas das vezes utilizada como pretexto para o ensino de conteúdos programáticos e destituída, assim, da sua dimensão estética. Para Lajolo (1994, p.16), as dificuldades que os alunos manifestam em relação à literatura são sintomas que denunciam o pouco contato dos professores com a leitura literária:

[...] o desencontro literatura-jovens que explode na escola parece mero sintoma de um desencontro maior, que nós - professores - também vivemos. Os alunos não leem, nem nós; os alunos escrevem mal e nós também. Mas, ao contrário de nós, os alunos não estáo investidos de nada. E o bocejo que oferecem à nossa explicação sobre o realismo fantástico de Incidente em Antares ou sobre a metalinguagem de Memórias Póstumas de Brás Cubas é incômodo e subversivo, porque sinaliza nossos impasses. Mas, sinalizando-os, ajuda a superá-los. Pois só superando-os é que em nossas aulas se pode cumprir, 
da melhor maneira possível, o espaço de liberdade e subversão que, em certas condições, instaura-se pelo e no texto literário.

Para que a relação entre crianças e textos literários se realize na plenitude que esse tipo de texto requer, os professores devem ser, eles mesmos, leitores, participantes ativos da cultura e do universo literário. Por sua vez, tornar-se leitor de literatura requer a apropriação de capacidades específicas e o domínio de competências que contribuam para a formação da pessoa, em permanente contato com textos do passado e do presente; para o reconhecimento da diversidade social e cultural, no encontro com grandes questóes que a leitura propicia; para perceber que a literatura "permite apreciar as infinitas possibilidades de estruturar e reestruturar os recursos da linguagem” (COLOMER, 2007, p. 31-32).

Vincent Jouve (2002) trata da complexidade característica da leitura literária, reportando-se a três funçóes básicas apontadas por Michel Picard, que seriam peculiares a esse tipo de leitura: "a subversão na conformidade", "a eleição do sentido na polissemia", "a modelização por uma experiência de realidade fictícia”.

Em relação à primeira função, “a subversão na conformidade”, o autor sugere que "o texto literário ao mesmo tempo contesta e supóe uma cultura" (JOUVE, 2002, p. 137). Dessa forma, uma inovação só pode ser entendida a partir da tradição. A leitura literária tem, portanto, um duplo interesse em nos mergulhar numa cultura e, ao mesmo tempo, explodir seus limites. De acordo com a segunda função, "a eleição do sentido na polissemia", "o texto literário remete sempre a uma pluralidade de significaçôes” (JOUVE, 2002, p. 137). Assim, "a leitura literária é, mais do que qualquer uma, marcada subjetivamente: enriquecedora no plano intelectual, autoriza também o investimento imaginário" (JOUVE, 2002, p. 137). Quanto à terceira função, "a modelização por uma experiência de realidade fictícia”, Jouve (2002, p. 137-138) afirma cumprir o papel pedagógico da leitura, ele propóe ao leitor "experimentar, no modo imaginário, uma cena que ele poderia viver na realidade: a leitura, em outras palavras, permite 'experimentar' situaçôes".

Considerando o que se privilegia na formação literária escolar, pode-se dizer que as três funçóes deveriam ser exploradas em contextos de formação, propiciando o esperado deslocamento do leitor para outros mundos e outras vivências, a partir do contato com o texto ficcional. 
Tendo como ponto de partida a importância dessa prática cultural, o Projeto Tertúlia Literária, embora não tenha como objetivo o ensino da literatura, reconhece que o trabalho voltado para a leitura literária na escola acontecerá de fato por meio do engajamento de educadores que sejam leitores da literatura. $\mathrm{O}$ papel desses leitores/mediadores é fundamental, sobretudo considerando o fato de o Brasil ainda não ser um País de leitores, como mostra a pesquisa Retratos da Leitura no Brasil, realizada pelo Instituto Pró-Livro/2011 ${ }^{1}$. Os dados da pesquisa reforçam a importância de a leitura literária ser trabalhada na escola por evidenciarem que é, na idade de escolarização obrigatória, ou seja, dos quatro aos dezessete anos, que se situa a maior parte dos leitores. Nessa faixa etária, o percentual de leitores é significativamente maior do que a de não leitores. Nas faixas etárias imediatamente subsequentes, leitores e não leitores se equiparam, e por fim esta categoria passa a ser majoritária nas faixas etárias mais avançadas.

Se esses dados acerca de leitores e não leitores tomados na sua generalidade não são animadores, quando se especifica a questão do tipo de leitura, considerando-se o número de livros de leitura literária lidos, vimos uma situação ainda mais preocupante. Reafirma essa ponderação o fato de que, ainda que entre os estudantes, a média de livros lidos nos últimos três meses (3,41 livros) seja bem maior do que o total registrado entre todos os entrevistados (1,85 livros), $65 \%$ dos livros lidos por esses estudantes, nos últimos três meses, foram lidos por terem sido indicados pela escola, dentre eles $78 \%$ eram livros didáticos. Embora pouco otimistas, os resultados da pesquisa reforçam o importante papel da escola na formação de leitores no país. Para alterar esse quadro, é necessário, portanto, assegurar, na formação de professores, livros "capazes de dar aos homens e mulheres um conhecimento melhor do mundo e da sociedade" (CHARTIER, 2014, p. 20), para que eles se sintam motivados a compartilhar essa experiência com seus alunos.

\section{Afinal, como contribuir para a formação literária do professor alfabetizador?}

Conforme já apresentado neste artigo, a formação do professor alfabetizador como leitor de literatura deveria ocupar certa centralidade nos cursos de formação inicial. Em que medida as experiências de leitura, no ambiente universitário, em especial nos cursos de Pedagogia, veem a formação do professor como um leitor de literatura? 
Uma breve consulta realizada pela internet revela que, em 39 universidades federais $^{2}$ que ofertam cursos presenciais de Pedagogia, apenas dezessete delas possuem, nas suas propostas curriculares ou nos seus respectivos planos de curso, disciplinas obrigatórias de literatura. Por outro lado, o número de universidades que ofertam disciplinas optativas é considerável (34 universidades). Cabe ainda assinalar que a análise das ementas de doze disciplinas a que tivemos acesso mostra que a totalidade delas se volta para a instrumentalização do professor no trabalho com a literatura em classes de crianças ou de jovens. Ainda que consideremos que o trabalho com literatura infantil e juvenil possa sensibilizar o futuro professor para a leitura literária de uma maneira mais ampla, o acesso a textos literários destinados a adultos e a reflexão a partir de suas leituras são fundamentais para a formação do professor como leitor. O levantamento realizado apontou em uma única ementa relativa à disciplina "Literatura e Educação" uma frase expressando claramente a intencionalidade de formar o professor como leitor de literatura: "O professor - leitor na constituição de leitores".

A leitura literária exige atenção, concentração, disciplina, já que o texto literário se caracteriza pela pluralidade de sentidos e pela potencial intertextualidade que oferece. $\mathrm{Na}$ aproximação com a leitura literária, observamse transformaçóes gradativas e deslocamentos que tiram os sujeitos de seu estado de comodidade que podem resultar em uma transformação ou reconfiguração de si mesmo e do mundo, como mostra Bernardo (2005, p. 18): "A ficção é boa, se e somente se, não tem tudo a ver com o leitor. Qual é a relação? Ora, o leitor que reconfigura o seu mundo, depois de ler uma ficção reconfiguradora, é parte desse mesmo mundo. Logo, ele termina, muitas vezes sem o perceber, por reconfigurar a si mesmo".

Levando-se em conta o papel de destaque que o professor exerce na formação de leitores, somado à noção de que suas próprias experiências como leitor influenciam sua postura profissional, parece procedente considerar, nas ações de formação, estratégias que permitam ao professor falar de si, de seu gosto literário, de suas dificuldades, de sua relação - difícil ou prazerosa - com a leitura. Dessa maneira, seria de se esperar que, no momento em que ocupar o lugar de mediador e de promotor de leitura, o professor permita que o pequeno leitor possa falar de sua experiência, tenha curiosidade e descubra também esse caminho particular. Espera-se, pois, que as trajetórias pessoais e profissionais dos docentes estejam preenchidas pelas suas experiências de leitor de literatura. 
A experiência é aqui entendida como a inserção e integração em práticas de leitura de textos literários efetivas, que supóem desde a interação solitária no ato de ler textos ficcionais ou poéticos até a socialização dessas leituras, junto a comunidades de leitores.

Como se verá a seguir, o Projeto de Extensão Universitária Tertúlia literária tem como pressuposto a ideia de que ler implica compartilhar espaços, construir pensamentos e aumentar as aprendizagens e as motivaçóes educativas. Uma das consequências dessa perspectiva é compreender a leitura náo como um processo individual, mas sim coletivo. Trata-se de conceber a leitura a partir de uma perspectiva dialógica, compreendendo o diálogo não apenas no sentido estrito do termo que seria uma das formas da interação verbal, mas, como nos alerta Bakhtin (1992, p. 122), compreendendo-o no seu sentido mais amplo, "[...] não apenas como comunicação em voz alta de pessoas colocadas face a face, mas toda comunicação verbal, de qualquer tipo que seja”.

Para Bakhtin (1992), o diálogo que se observa no encontro do leitor com o livro promove uma infinidade de outros encontros expressos nas vozes de outros autores, outros leitores, críticos, resenhistas etc.

O livro, isto é, o ato de fala impresso, constitui igualmente um elemento da comunicação verbal. Ele é objeto de discussóes ativas sob a forma de diálogo e, além disso, é feito para ser apreendido de maneira ativa, para ser estudado a fundo, comentado e criticado no quadro do discurso interior, sem contar as reaçôes impressas, institucionalizadas, que encontram nas diferentes esferas da comunicação verbal (críticas, resenhas, que exercem influência sobre os trabalhos posteriores, etc.). Além disso, o ato de fala sob a forma de livro é sempre orientado em função das intervençôes anteriores na mesma esfera de atividades, tanto as do próprio autor como as de outros autores: ele decorre portanto da situação particular de um problema científico ou de um estudo de produção literária. Assim, o discurso escrito é de certa maneira parte integrante de uma discussão ideológica em grande escala: ele responde a alguma coisa, refuta, confirma antecipa as respostas e objeçóes potenciais, procura apoio, etc. (BAKHTIN, 1992, p. 123). 
A condição dialógica dos textos pressupóe, portanto, encontros que materializam o que Bakhtin formulou acerca da alteridade na construção da identidade, "os outros constituem dialogicamente o eu que se transforma dialogicamente num outro de novos eus" (FARACO, 2007, p. 106).

Trazer esta noção para o âmbito da formação de leitores implica ampliar as possibilidades de interação em torno de atividades de leitura, compreendendo o ato de ler não mais como um processo solitário entre o leitor e o texto, mas sim como um processo que se constrói coletivamente. Isto é o que propõe o Projeto Tertúlia Literária como se verá a seguir.

\section{Tertúlia Literária: uma proposta de formação de professores/ leitores de literatura}

O projeto Tertúlia Literária, a partir de uma perspectiva de leitura dialógica, concebe a prática da leitura literária como uma atividade propícia ao estabelecimento de relaçóes intersubjetivas, favorecendo a ampliação da circulação de textos escritos e a promoção de experiências diversificadas entre leitores.

O Projeto surgiu da insatisfação com os rumos que a formação de leitores literários vem tomando na escola de educação básica, especialmente na educação infantil e nos anos iniciais do ensino fundamental. Nas últimas décadas, sob diferentes enfoques, as pesquisas e estudos vêm se dedicando a compreender melhor o fenômeno da alfabetização das crianças e vêm resultando em variadas proposiçóes que impactam nas políticas públicas e nas práticas educativas. Alguns fatores têm contribuído para que esta questão ganhe destaque no cenário educacional brasileiro e para que haja, no seio da sociedade, uma pressão para que a alfabetização ocorra em idades cada vez mais precoces. Dentre esses fatores, destacamos a inclusão das crianças de seis anos de idade no ensino fundamental que passou a ter a duração de nove anos - Lei no 11.274/2006 (BRASIL, 2006), a obrigatoriedade da matrícula na pré-escola, para crianças a partir dos quatro anos de idade - Emenda 59/2009 (BRASIL, 2009); Lei 12.796/2013 (BRASIL, 2013a) - e a criação do Pacto Nacional de Alfabetização na Idade Certa (PNAIC), cuja finalidade é a de promover a alfabetização dos estudantes até os oito anos de idade ou ao final do terceiro ano do ensino fundamental (BRASIL, 2013b).

Quanto à inclusão das crianças de seis anos no ensino fundamental ${ }^{3}$, sua entrada, via de regra, é acompanhada da expectativa, por parte dos profissionais, 
gestores da área da Educação e familiares das crianças, de que a apropriação do sistema de escrita ocorra já nesse primeiro ano. Essa expectativa acaba por refletir na etapa anterior, ou seja, passa-se a imputar à educação infantil a tarefa de preparar para esse aprendizado.

Com relação à obrigatoriedade da matrícula na educação infantil a partir dos quatro anos, há um receio de que essa determinação legal reforce uma tendência já observada em alguns currículos de instituições educativas de se privilegiarem práticas e atividades voltadas para a consolidação do processo de alfabetização antes mesmo da entrada da criança no ensino fundamental.

Finalmente, a promulgação do PNAIC estabeleceu a alfabetização como uma prioridade para o ensino das crianças de seis a oito anos. Ainda que não seja sua intenção formal, o PNAIC pode, em curto prazo, atribuir à pré-escola, agora obrigatória, função preparatória. Já se observa, em alguns municípios, a incorporação de professores(as) da educação infantil ao PNAIC, sem que esse programa contemple discussóes específicas da primeira etapa da educação básica e sua relação com a aprendizagem da linguagem escrita.

Essas e outras alterações no âmbito das políticas públicas vêm influenciando mudanças nas práticas pedagógicas. Em muitos casos, o ensino da leitura e da escrita ocorre de forma dicotomizada, separando-se o processo de apropriaçáo do sistema de escrita do desenvolvimento de habilidades e capacidades que assegurem à criança sua condição de membro da cultura escrita. A literatura, nesse contexto, vem recebendo um tratamento indesejável, ora servindo prioritariamente como estratégia didática para a aquisição da base alfabética, ora concebida como mera atividade de fruição.

Como afirmamos acima, a formação do leitor literário é tarefa urgente e complexa, cujo êxito depende em grande medida da familiaridade que os professores têm com a literatura. O repertório cultural e as experiências de leitura dos professores são elementos decisivos para a garantia de uma mediação mais apropriada, capaz de aproximar as crianças dos livros de literatura e proporcionar-lhes uma trajetória de formação como leitores perenes.

O compromisso do Projeto Tertúlia Literária de aproximar os professores da educação infantil e dos anos iniciais do ensino fundamental da literatura escrita para adultos se consolida por meio da estratégia de se destacar, em primeiro plano, a condição de leitor e não de professor. Embora os participantes possuam essa identidade profissional comum, para o Projeto eles são leitores 
que se encontram para compartilhar suas leituras, sem o objetivo de transpor a experiência de leitura dos livros lidos em possibilidades didáticas, aplicáveis na sala de aula. O que parece ser uma contradição, na verdade, é um princípio: só abandonando a "função" professor, se consegue um mergulho na obra, sem pensá-la unicamente como um texto passível de utilização em práticas escolares com os seus alunos, mesmo que isso venha acontecer um dia sob outras bases. Parte-se do pressuposto de que para alcançarem experiências duradouras de leitura literária, que, de fato, transformem os leitores, importa muito a intenção de ler para "penetrar no bosque" sem a ligeireza dos atalhos, "andar para ver como é o bosque e descobrir por que algumas trilhas são acessíveis e outras não" (ECO, 1994, p. 33).

\section{Como funciona o Projeto Tertúlia literária}

O Projeto Tertúlia literária estrutura-se em ediçóes anuais. A cada edição é escolhido um tema e, a partir dele, são selecionadas obras literárias, cujas leituras mensais são indicadas previamente aos participantes. Desde a primeira edição, o Projeto conta com a participação de professores da educaçáo infantil e dos anos iniciais do ensino fundamental de escolas públicas e, em número menor, alunos dos cursos de Letras, Ciências da Informação, Artes Cênicas e Pedagogia da Universidade Federal de Minas Gerais (UFMG). Em cada uma das ediçóes, constitui-se um grupo de aproximadamente quarenta participantes. Como contrapartida das redes de ensino, que fazem adesão e se inscrevem para participar do Projeto, os livros indicados são comprados para todos os professores, que, assim, passam a construir a sua biblioteca pessoal. Cabe ainda às Prefeituras assegurar o transporte e dispensar os professores das suas atividades regulares profissionais, uma vez por mês, para que possam participar da sessão presencial.

A partir da definição da temática e dos títulos que integrarão a edição, os participantes do-Tertúlia realizam as leituras dos livros na ordem indicada. No período que antecede o encontro presencial, durante o mês em que ocorre a leitura do livro, os participantes se comunicam por meio do site do Projeto ${ }^{4}$. Nos fóruns de discussão, criados no espaço web, são realizados debates sobre a temática ou sobre algum aspecto relacionado à leitura da obra. Também no site, os participantes encontram indicaçóes de leitura de outros textos, tais como: letras de músicas, poesias, reportagens ou acessam outras obras literárias 
relacionadas à temática daquela edição. Também assistem a filmes, vídeos ou veem imagens postadas pelos coordenadores do Projeto, com o objetivo de estimular a curiosidade e o desejo de ler e conversar sobre os livros que estáo lendo. Ao fim desse período, ocorre o encontro presencial, no qual se efetiva a troca de experiências, por meio de discussóes que ampliam a leitura realizada. Nesses encontros, um convidado, que pode ser um autor de textos literários, um professor, um livreiro, um ilustrador, um pesquisador, ou simplesmente um leitor apaixonado pela obra em foco, cumpre o papel de conduzir os debates, suscitando a manifestação das experiências individuais de leitura por cada participante. Nessa conversa, expóem-se livremente aspectos sobre a obra, a vida do autor ou o contexto no qual foi produzida, com vistas à interação do grupo participante.

A experiência de seis ediçóes do Projeto mostrou que a interlocução entre o leitor convidado e os participantes tem resultado em importante e proveitosa oportunidade de ampliação da bagagem literária e de desenvolvimento das habilidades de leitura. A abordagem que o convidado faz da obra torna-se, assim, um componente que se soma à experiência de cada participante, sob novos ângulos, que impulsionam o desejo pela releitura.

Ao longo do encontro, os participantes são convidados a partilhar suas próprias experiências. Nas exposiçóes das leituras individuais, percebe-se como as obras repercutem em suas vidas, de que forma e com que intensidade os leitores se apropriam do que leram e como o fazem. Em algumas situaçóes, nota-se que, apesar de muitas vezes terem ouvido falar da obra, de seus personagens ou de seu autor, não haviam ainda se aventurado a desbravar as páginas desses livros. Para tornar a reunião ainda mais agradável, a cada encontro do Tertúlia um grupo de participantes é indicado para preparar um lanche que será compartilhado por todos durante ou ao término da sessáo presencial.

Em cada uma das ediçôes, ocorre uma sessão especial ao final do ano, organizada de acordo com a temática abordada. Na segunda edição, por exemplo, ocorrida em 2010, cujo tema foi "O amor na literatura", a atividade foi uma visita ao Teatro Municipal de Sabará, construído em 1818, como ambientação para o livro Romeu e Julieta. O professor convidado, especialista em artes cênicas, criou um contexto para a discussáo da obra de Shakespeare, apresentando informaçóes sobre o teatro elisabetano, a forma de apresentação das peças nos séculos XV e XVI, as diferentes versôes da obra, suas traduçôes 
para o português e finalizou com uma leitura dramática da peça. Na quarta edição, cujo tema foi "O crime na literatura", a atividade de encerramento foi uma visita ao cemitério do Bonfim, em Belo Horizonte, acompanhada por uma professora de Artes Visuais da Universidade Estadual de Minas Gerais, que fez um percurso guiado, mostrando os estilos e aspectos artísticos presentes nos mausoléus. Na quinta edição, como o tema era "A fofoca na literatura" e considerando os cinco anos do Projeto, a sessão de encerramento foi uma festa de comemoração, com o lançamento de um almanaque sobre todas as edições anteriores. Já na sexta edição, "Literatura e direitos humanos", o grupo visitou o Memorial da Resistência em São Paulo e fez uma imersão histórica no período da Ditadura Militar.

Os temas contemplados de 2009 a 2014, como se verá mais detalhadamente na tabela a seguir, foram os seguintes: a infância na literatura; o amor na literatura; a viagem na literatura; o crime na literatura; a fofoca na literatura; Literatura e direitos humanos, respectivamente.

Tabela 1 - Tema, ano, títulos dos livros lidos, autores, convidados e data das sessóes de acordo com cada ediçáo do Projeto Tertúlia Literária

\begin{tabular}{|l|l|l|l|l|l|l|}
\hline Ediçáo & Ano & Tema & Livros lidos & Autores & Convidados & Sessáo \\
\hline & & & $\begin{array}{l}\text { Indez, Por } \\
\text { parte de pai; } \\
\text { Ler, escrever, } \\
\text { fazer conta de } \\
\text { cabeça }\end{array}$ & $\begin{array}{l}\text { Bartolomeu } \\
\text { Campos de } \\
\text { Queiroz }\end{array}$ & $\begin{array}{l}\text { Prof. Hércules } \\
\text { Toledo }\end{array}$ & $\begin{array}{l}29 \text { de } \\
\text { mai. }\end{array}$ \\
Primeira \\
ediçáo
\end{tabular}




\begin{tabular}{|c|c|c|c|c|c|c|}
\hline Ediçấo & Ano & Tema & Livros lidos & Autores & Convidados & Sessão \\
\hline \multirow{6}{*}{$\begin{array}{l}\text { Segunda } \\
\text { ediçâao }\end{array}$} & \multirow{6}{*}{2010} & \multirow{5}{*}{$\begin{array}{l}\text { O amor na } \\
\text { literatura }\end{array}$} & $\begin{array}{l}13 \text { dos } \\
\text { melhores } \\
\text { contos de amor } \\
\text { da literatura }\end{array}$ & $\begin{array}{l}\text { Org. de Rosa } \\
\text { Amanda } \\
\text { Strausz }\end{array}$ & $\begin{array}{l}\text { Prof. Carlos } \\
\text { Novais }\end{array}$ & $\begin{array}{l}25 \text { de } \\
\text { jun. }\end{array}$ \\
\hline & & & $\begin{array}{l}\text { Romeu e } \\
\text { Julieta }\end{array}$ & $\begin{array}{l}\text { William } \\
\text { Shakespeare }\end{array}$ & $\begin{array}{l}\text { Prof. José } \\
\text { Simóes }\end{array}$ & $\begin{array}{l}27 \mathrm{de} \\
\text { ago. }\end{array}$ \\
\hline & & & $\begin{array}{l}\text { O beijo da } \\
\text { mulher aranha }\end{array}$ & Manuel Puig & $\begin{array}{l}\text { A equipe de } \\
\text { coordenaçắo }\end{array}$ & $\begin{array}{l}24 \text { de } \\
\text { set. }\end{array}$ \\
\hline & & & $\begin{array}{l}\text { O amor nos } \\
\text { tempos do } \\
\text { cólera }\end{array}$ & $\begin{array}{l}\text { Gabriel } \\
\text { García } \\
\text { Márquez }\end{array}$ & $\begin{array}{l}\text { Prof. Marcos } \\
\text { Alexandre }\end{array}$ & $\begin{array}{l}29 \text { de } \\
\text { out. }\end{array}$ \\
\hline & & & $\begin{array}{l}\text { A hora da } \\
\text { estrela }\end{array}$ & $\begin{array}{l}\text { Clarice } \\
\text { Lispector }\end{array}$ & $\begin{array}{l}\text { Prof.Aparecida } \\
\text { Paiva }\end{array}$ & $\begin{array}{l}26 \text { de } \\
\text { nov. }\end{array}$ \\
\hline & & \multirow{5}{*}{$\begin{array}{l}\text { A viagem } \\
\text { na } \\
\text { literatura }\end{array}$} & Odisseia & Homero & $\begin{array}{l}\text { Prof. Jacinyho } \\
\text { Lyns Brandão }\end{array}$ & $\begin{array}{l}27 \mathrm{de} \\
\text { mai. }\end{array}$ \\
\hline \multirow{4}{*}{$\begin{array}{l}\text { Terceira } \\
\text { Ediçáo }\end{array}$} & \multirow{4}{*}{2011} & & $\begin{array}{l}\text { Crônicas } \\
\text { Marcianas }\end{array}$ & $\begin{array}{l}\text { Ray } \\
\text { Bradbury }\end{array}$ & $\begin{array}{l}\text { Prof. Jeter } \\
\text { Neves }\end{array}$ & $\begin{array}{l}01 \text { de } \\
\text { jul. }\end{array}$ \\
\hline & & & $\begin{array}{l}\text { Terra } \\
\text { Sonâmbula }\end{array}$ & Mia Couto & $\begin{array}{l}\text { Prof. Maria } \\
\text { Zilda Cury }\end{array}$ & $\begin{array}{l}26 \text { de } \\
\text { ago. }\end{array}$ \\
\hline & & & $\begin{array}{l}\text { Duas viagens } \\
\text { ao Brasil }\end{array}$ & Hans Staden & $\begin{array}{l}\text { Prof. Eliane } \\
\text { Marta }\end{array}$ & $\begin{array}{l}30 \text { de } \\
\text { set. }\end{array}$ \\
\hline & & & $\begin{array}{l}\text { As viagens de } \\
\text { Gulliver }\end{array}$ & $\begin{array}{l}\text { Jonathan } \\
\text { Swift }\end{array}$ & $\begin{array}{l}\text { Prof. Luiz } \\
\text { Cláudio de } \\
\text { Oliveira }\end{array}$ & $\begin{array}{l}21 \mathrm{de} \\
\text { out. }\end{array}$ \\
\hline \multirow{5}{*}{$\begin{array}{l}\text { Quarta } \\
\text { Ediçāoo }\end{array}$} & \multirow{5}{*}{2012} & \multirow{5}{*}{$\begin{array}{l}\text { O crime na } \\
\text { literatura }\end{array}$} & Vidas Secas & $\begin{array}{l}\text { Graciliano } \\
\text { Ramos }\end{array}$ & $\begin{array}{l}\text { Prof. Luis } \\
\text { Carlos Maciel }\end{array}$ & $\begin{array}{l}25 \mathrm{de} \\
\text { nov. }\end{array}$ \\
\hline & & & $\begin{array}{l}\text { Histórias } \\
\text { extraordinárias }\end{array}$ & $\begin{array}{l}\text { Edgar Allan } \\
\text { Poe }\end{array}$ & $\begin{array}{l}\text { Prof. Jeter } \\
\text { Neves }\end{array}$ & $\begin{array}{l}25 \mathrm{de} \\
\text { mai. }\end{array}$ \\
\hline & & & $\begin{array}{l}\text { Travessuras da } \\
\text { menina má }\end{array}$ & $\begin{array}{l}\text { Mario Vargas } \\
\text { Llosa }\end{array}$ & $\begin{array}{l}\text { Prof. Juliana } \\
\text { Leal }\end{array}$ & $\begin{array}{l}31 \text { de } \\
\text { ago. } \\
\text { (pós } \\
\text { greve) }\end{array}$ \\
\hline & & & $\begin{array}{l}\text { Crime e } \\
\text { Castigo }\end{array}$ & $\begin{array}{l}\text { Fiódor } \\
\text { Dostoiévski }\end{array}$ & $\begin{array}{l}\text { Prof. Luiz } \\
\text { Cláudio }\end{array}$ & $\begin{array}{l}28 \text { de } \\
\text { set. }\end{array}$ \\
\hline & & & $\begin{array}{l}\text { A alma } \\
\text { encantadora } \\
\text { das ruas }\end{array}$ & Joâo do Rio & $\begin{array}{l}\text { Prof. Maria } \\
\text { Zilda }\end{array}$ & $\begin{array}{l}26 \text { de } \\
\text { out. }\end{array}$ \\
\hline
\end{tabular}



dores na universidade

\begin{tabular}{|c|c|c|c|c|c|c|}
\hline Ediçáo & Ano & Tema & Livros lidos & Autores & Convidados & Sessão \\
\hline $\begin{array}{l}\text { Quinta } \\
\text { edição }\end{array}$ & 2013 & $\begin{array}{l}\text { A fofoca na } \\
\text { literatura }\end{array}$ & $\begin{array}{l}\text { Édipo rei } \\
\text { Hamlet } \\
\text { O crime do } \\
\text { padre Amaro } \\
\text { Lavoura } \\
\text { Arcaica } \\
\text { Muito barulho } \\
\text { por nada } \\
\text { Ligaçôes } \\
\text { perigosas } \\
\text { Crônicas da } \\
\text { casa assassinada } \\
\text { Madame } \\
\text { Bovary } \\
\text { Dom } \\
\text { Casmurro e } \\
\text { Otelo } \\
\text { O leite } \\
\text { derramado } \\
\text { O anjo } \\
\text { pornográfico } \\
\text { Cyro e } \\
\text { Drummond }\end{array}$ & $\begin{array}{l}\text { Sófocles } \\
\text { Shakespeare } \\
\text { Eça de } \\
\text { Queirós } \\
\text { Raduan } \\
\text { Nassar } \\
\text { Shakespeare } \\
\text { Choderlos de } \\
\text { Laclos } \\
\text { Lúcio } \\
\text { Cardoso } \\
\text { Gustave } \\
\text { Flaubert } \\
\text { Machado } \\
\text { de Assis e } \\
\text { Shakespeare } \\
\text { Chico } \\
\text { Buarque } \\
\text { Ruy Castro } \\
\text { Carlos } \\
\text { Drummond } \\
\text { e Cyro dos } \\
\text { Anjos }\end{array}$ & $\begin{array}{l}\text { Prof. Jacinyho } \\
\text { Lyns Brandáo } \\
\text { Prof. Jacinyho } \\
\text { Lyns Brandão } \\
\text { Prof. Silvana } \\
\text { Pessoa } \\
\text { Prof. Lucia } \\
\text { Castelo Branco } \\
\text { Prof. Raquel } \\
\text { Castro } \\
\text { Prof. Carlos } \\
\text { Versiani } \\
\text { Prof. Marcos } \\
\text { Rogério } \\
\text { Cordeiro } \\
\text { Prof. Luis } \\
\text { Carlos Maciel } \\
\text { Prof. Magda } \\
\text { Soares } \\
\text { Prof. Sergio } \\
\text { Fantini } \\
\text { Prof. Samira } \\
\text { Almeida } \\
\text { Prof. Sérgio } \\
\text { Alcides }\end{array}$ & $\begin{array}{l}09 \text { de } \\
\text { nov. } \\
09 \text { de } \\
\text { nov. } \\
23 \text { de } \\
\text { nov. } \\
07 \text { de } \\
\text { dez. } \\
25 \text { de } \\
\text { mai. } \\
31 \text { de } \\
\text { ago. } \\
\text { (pós } \\
\text { greve) } \\
28 \text { de } \\
\text { set. } \\
26 \text { de } \\
\text { out. } \\
09 \text { de } \\
\text { nov. } \\
09 \text { de } \\
\text { nov. } \\
23 \text { de } \\
\text { nov. } \\
07 \text { de } \\
\text { dez. }\end{array}$ \\
\hline
\end{tabular}




\begin{tabular}{|c|c|c|c|c|c|c|}
\hline Edição & Ano & Tema & Livros lidos & Autores & Convidados & Sessão \\
\hline $\begin{array}{l}\text { Sexta } \\
\text { ediçấo }\end{array}$ & 2014 & $\begin{array}{l}\text { Os direitos } \\
\text { humanos } \\
\text { na } \\
\text { literatura }\end{array}$ & $\begin{array}{l}\begin{array}{l}\text { Eles eram } \\
\text { muitos cavalos } \\
\text { Poemas } \\
\text { Sentimento do } \\
\text { mundo }\end{array} \\
\text { São Bernardo } \\
\text { Vila Vermelho } \\
\text { e Pantanáutilos } \\
\text { Grande sertáo: } \\
\text { veredas } \\
\text { Poetas de } \\
\text { Moçambique }\end{array}$ & $\begin{array}{l}\text { Luiz Ruffato } \\
\text { Wislawa } \\
\text { Szymborska } \\
\text { Carlos } \\
\text { Drummond } \\
\text { de Andrade } \\
\text { Graciliano } \\
\text { Ramos } \\
\text { Jeter Neves e } \\
\text { Ana Carolina } \\
\text { Neves } \\
\text { Guimarães } \\
\text { Rosa } \\
\text { Rui Knopfli }\end{array}$ & $\begin{array}{l}\text { Prof. Ivete } \\
\text { Walty } \\
\text { Prof. Ana Elisa } \\
\text { Ribeiro } \\
\text { Prof. Silvana } \\
\text { Pessoa } \\
\text { Prof. Graça } \\
\text { Paulino } \\
\text { Prof. Jeter } \\
\text { Neves } \\
\text { Prof. Luiz } \\
\text { Cláudio } \\
\text { Oliveira } \\
\text { A equipe de } \\
\text { coordenação }\end{array}$ & \begin{tabular}{|l}
28 de \\
mar. \\
25 de \\
abr. \\
30 de \\
mai. \\
29 de \\
ago. \\
26 de \\
set. \\
\\
31 de \\
out. \\
28 de \\
nov.
\end{tabular} \\
\hline
\end{tabular}

Fonte: Autoras

A escolha dos livros por tema favorece uma variedade de propostas e estilos literários que abarcam obras que cumpriram ou cumprem uma circulação/ recepção também muito variada no campo da literatura. No âmbito do tema infância, por exemplo, os participantes leram desde obras como $O$ meu pé de laranja lima, de José Mauro de Vasconcelos, até Miguilim, de João Guimarães Rosa; no eixo temático que contemplou a viagem, as sessóes foram abertas com o clássico Odisséia, de Homero, e passaram por outros livros como Vidas Secas, de Graciliano Ramos, e Terra Sonâmbula, de Mia Couto. No tratamento do amor, foi traçado um panorama histórico do que se entende por amor, desde a época clássica, passando pelo amor romântico, parnasiano, modernista, com uma interessante interrogação sobre como esse sentimento é compreendido nos dias atuais. Leituras de textos dramáticos, poemas, narrativas, crônicas, memórias são exemplos da diversidade de obras e autores que foram lidos nas diversas sessóes que aconteceram ao longo desses seis anos.

A garantia da diversidade na organização e na estruturação de cada sessão é um princípio do Projeto. Há situações em que o próprio grupo de coordenação se encarrega das sessóes propondo dinâmicas relacionadas às temáticas e aos 
livros lidos, debates, apresentando obras de arte, filmes baseados na obra literária lida, traçando perfis, fazendo aproximaçóes, reconhecimentos, enfim, dando abertura para um tratamento que resulta, finalmente, na formação cultural do sujeito leitor. Em outras situaçóes, os convidados conduzem as discussóes, assumindo um tom mais acadêmico ou construindo estratégias que facilitam uma construçáo mais participativa e menos expositiva.

Qualquer que seja o formato assumido há uma preocupação comum: garantir que os leitores expressem suas opinióes e suas satisfaçóes ou insatisfaçóes, articulem novos pensamentos, exteriorizem elementos perturbadores provocados pela história. Nessa "conversação literária", como assinala Chambers (2007), a fala sobre o que se leu dá forma aos pensamentos e emoçôes excitados pelo livro e pelos significados que construímos juntos a partir do texto: "Náo sabemos o que pensamos sobre um livro até que falamos sobre ele" (CHAMBERS, 2007, p. 19).

Essa é uma outra finalidade do Projeto, construir situaçóes e espaços nos quais os sujeitos possam olhar para si e para os outros a partir de ângulos e lentes variadas, constituindo-se, assim, como leitores que entendem e respeitam a diversidade. Dessa forma, vão-se construindo sentidos partilhados e as sessōes passam a ser um espaço no qual a intersubjetividade é motivada pela liberdade de se posicionar como um sujeito produtor de sentidos. Como afirma Vincent Jouve (2002, p. 102):

O eu que se engaja na obra sempre é, de fato, ele próprio um texto: o sujeito não é nada mais do que a resultante de influências múltiplas. A interação que se produz na leitura é, portanto, sempre inédita. O sentido, longe de ser imanente, se apresenta como o resultado de um encontro: o do livro e do leitor.

\section{À Guisa de reflexões}

Durante esses seis anos de existência do Projeto, pôde-se perceber uma variedade de situaçôes que indicam o alcance da sua proposta e os necessários ajustes para sua manutençáo. Se, de um lado, o Projeto avançou ao abrir espaços para novos interlocutores, por meio da presença de convidados, por outro lado, percebe-se a necessidade de se precisar melhor as demandas, estabelecendo com maior clareza o seu princípio fundamental de dar voz aos leitores, qualquer que venha a ser a opção assumida pelos participantes. 
Como assinalamos acima, alguns dos convidados preferem um formato mais tradicional, assegurando que sua fala contemple um amplo espectro de informaçóes a respeito do livro, outros, por sua vez, tendem a privilegiar certos tópicos e a empregar estratégias e dinâmicas para garantir uma qualidade de debate entre o grupo de leitores/professores. Essa variedade de mediaçóes tem sido benéfica às dinâmicas propostas, uma vez que tantos são os leitores quantas são as suas maneiras de falar sobre as suas leituras.

Outro aspecto positivo é o contato acadêmico com colegas de outros setores, unidades, faculdades ou universidades, que compreendem a proposta $\mathrm{e}$ se engajam com sensibilidade e interesse nesse trabalho. Seriam bem-vindas açóes mais integradoras entre o Projeto e as demais atividades acadêmicas realizadas na Faculdade de Educação, em outras unidades da UFMG e até mesmo em outras instituiçôes, que pudessem enriquecer e ampliar as açóes de formação de professores, em que o trabalho com a linguagem literária estivesse no centro das nossas preocupaçóes.

A convivência com a heterogeneidade de pontos de vista tem propiciado aos participantes do Projeto Tertúlia Literária tomarem para si a liberdade de interpretação, sem cair na armadilha do "pode tudo", que, em geral, afasta o leitor da interlocuçáo com as temáticas do livro. Esse é mais um dos princípios estruturantes do Projeto, a construção de uma autonomia de leitura, no diálogo com outros leitores. Vale lembrar que o conceito de autonomia sinaliza um leitor com condiçóes próprias que o levem a produzir sentido(s) na leitura, por isso, não se deve esquecer que essa autonomia é construída por um entrelaçamento de pensamentos que se organizam num todo coletivo e a interação com seus pares torna-se, dessa forma, fundamental.

Outro aspecto a destacar é a instabilidade inicial do grupo em relação ao seu direito de fala e sua transformação gradativa ao longo do processo por que vai passando durante a vigência do Projeto. Muitos permanecem ainda simplesmente como ouvintes e outros tomam o turno para emitir opinióes, relacionar a problemática com suas vidas, apresentar dúvidas de leitura. Todavia, parte significativa dos ouvintes vai, aos poucos, assumindo uma postura mais ativa e notam-se mudanças frente à explanaçáo do convidado: um olhar mais participativo, um silêncio compreensivo, sorrisos ou mesmo um semblante de discordância, a atenção à releitura de trechos comentados com o livro em mãos, gestos e expressóes que denotam uma postura de seriedade e engajamento na proposta. É comum, ao final do ano, a ocorrência de pedidos de professores que desejam continuar no Projeto, independentemente da adesão da Prefeitura de seu município. 
Essa vontade individual foi, na verdade, sendo construída aos poucos pela relação do leitor com as finalidades do Projeto, do leitor com a coordenação e com seus colegas e do leitor consigo mesmo, através da experiência da mediação. Livros considerados 'cânones' no campo literário, ao lado de outros, foram lidos, debatidos, interpretados e ressignificados, sinalizando a importância do caráter mediador na busca do protagonismo desse leitor literário, o que justifica a nossa máxima de que "quem lê também tem muito a dizer".

Essas reflexóes nos levam a supor que, da mesma forma que ocorre com as crianças bem pequenas, não sabemos exatamente quando e como os seres humanos realizam uma síntese do que sabem e a partir dela avançam, mas uma coisa é certa: a convivência com a literatura pode ser uma porta para o entendimento do mundo ainda a ser explorado. O seu sentido e a sua força residem na pluralidade de certezas e incertezas que perpassam os textos literários de diferentes épocas, como um amplo mosaico da condição humana, com as suas conquistas e fragilidades. Dessa forma, podemos considerar que uma formação integral do professor, seja da educação infantil, dos anos iniciais ou dos anos subsequentes, deve passar por uma compreensão de que as linguagens abarcam formas inusitadas de expressão e que a dimensão estética da literatura é uma delas.

\section{Notas}

${ }^{1}$ Disponível em: <http://prolivro.org.br/home/images/relatorios_boletins/3_ ed_pesquisa_retratos_leitura_IPL.pdf >. Acesso em: 18 nov. 2015.

${ }^{2}$ Conforme consulta ao site do Ministério da Educação, atualmente existem 63 universidades federais no País, sendo que 48 delas ofertam cursos presenciais de Pedagogia. Por meio dos endereços eletrônicos, acessaram-se 37 grades curriculares ou projetos pedagógicos dos cursos. Em alguns casos foi possível ter acesso às disciplinas e às suas respectivas ementas. A partir de solicitação encaminhada por e-mail, mais dois projetos de curso foram disponibilizados, perfazendo um total de 39 currículos analisados.

${ }^{3}$ Em alguns sistemas de ensino, as crianças estão sendo matriculadas no ensino fundamental aos cinco anos de idade, em contraposiçáo às determinaçôes do Conselho Nacional de Educação de que a matrícula ocorra com seis anos completos ou a completar até o dia 31 de março. Para aprofundar essa questáo ver Baptista e Lima (2013). 
${ }^{4}$ Para conhecer o site do Projeto Tertúlia Literária, acesse: <http://www. fae.ufmg.br/tertulia/>.

5 Almanaque Comemorativo 5 anos do Tertúlia disponível em: <http:// issuu.com/philippealbuquerque/docs/almanaques.

\section{REFERÊNCIAS}

BAPTISTA, Mônica Correia; LIMA, Rosalba Rita (Org.). Dossiê FMEI: 5 anos é na educação infantil. Belo Horizonte: UFMG/Faculdade de Educação, 2013. Disponível em: <http://www.ded.ufla.br/forumsulmineiro/ imagens/Dossi\%EA\%20FMEI_5\%20Anos\%20\%E9\%20na\%20 Educa\%E7\%E3o\%20Infantil.pdf>. Acesso em: 5 jul. 2014.

BAKHTIN, Mikhail (Volochinov). Marxismo e filosofia da linguagem. 6. ed. São Paulo: Hucitec, 1992.

BERNARDO, Gustavo. A qualidade da invenção. In: OLIVEIRA, Ieda (Org.). O que é qualidade em literatura infantil e juvenil? Com a palavra, o escritor. São Paulo: DCL, 2005. p. 9-24.

BRASIL. Lei 11.274, de 6 de fevereiro de 2006. Altera a redação dos arts. 29, 30, 32 e 87 da Lei no 9.394, de 20 de dezembro de 1996, que estabelece as diretrizes e bases da educação nacional, dispondo sobre a duração de 9 (nove) anos para o ensino fundamental, com matrícula obrigatória a partir dos 6 (seis) anos de idade. Diário Oficial da União, Brasília, DF, 7 fev. 2006. Disponível em: <http://www.planalto.gov.br/ccivil_03/_Ato20042006/2006/Lei/l11274.htm>. Acesso em: 6 jul. 2014.

BRASIL. Emenda Constitucional 59, de 11 de novembro de 2009. Acrescenta $₫ 3^{\circ}$ ao art. 76 do Ato das Disposiçóes Constitucionais Transitórias para reduzir, anualmente, a partir do exercício de 2009, o percentual da Desvinculação das Receitas da União incidente sobre os recursos destinados à manutenção e desenvolvimento do ensino de que trata o art. 212 da Constituição Federal, dá nova redaçâo aos incisos I e VII do art. 208, de forma a prever a obrigatoriedade do ensino de quatro a dezessete anos e ampliar a abrangência dos programas suplementares para todas as etapas da educação básica, e dá nova redação ao $\$ 4^{\circ}$ do art. 211 e ao $\$ 3^{\circ}$ do art. 212 e ao caput do art. 214, com a inserção neste dispositivo de inciso VI. Diário Oficial Uniāo, Brasília, DF, 12 nov. 2009. Disponível em: <http://www.planalto.gov. br/ccivil_03/constituicao/Emendas/Emc/emc59.htm>. Acesso em: 6 jul. 2014. 
BRASIL. Lei 12.796, de 4 de abril de 2013. Altera a Lei nº.9.394, de 20 de dezembro de 1996, que estabelece as diretrizes e bases da educação nacional, para dispor sobre a formação dos profissionais da educação e dar outras providências. Diário Oficial da Uniāo, Brasília, DF, 5 abr. 2013a. Disponível em: <http:/www.planalto.gov.br/ccivil_03/_ato2011-2014/2013/lei/112796. htm>. Acesso em: 6 jul. 2014.

BRASIL. Lei 12.801, de 24 de abril de 2013. Dispóe sobre o apoio técnico e financeiro da Uniấo aos entes federados no âmbito do Pacto Nacional pela Alfabetizaçáo na Idade Certa e altera as Leis n $\underline{\text { 오 }} 5.537$, de 21 de novembro de 1968, 8.405, de 9 de janeiro de 1992, e 10.260, de 12 de julho de 2001. Diário Oficial da Uniāo, Brasília, DF, 25 abr. 2013b. Disponível em: <http:// www.planalto.gov.br/ccivil_03/_Ato2011-2014/2013/Lei/L12801.htm>. Acesso em: 6 jul. 2014.

CHAMBERS, Aidan. Dime: los niños, la lectura y la conversación. México: FCE, 2007.

CHARTIER, Roger. A leitura como prática cultural. Revista Observatório Itaú Cultural, São Paulo, n.17, ago./dez. 2014).

COLOMER, Teresa. Andar entre livros: a leitura literária na escola. São Paulo: Global, 2007.

ECO, Umberto. Seis passeios pelo bosque da fiçẫo. Tradução de Hildegard Feist. São Paulo: Cia. das Letras, 1994.

FARACO, Carlos Alberto. O dialogismo como chave de uma antropologia filosófica. In: FARACO, Carlos Alberto; TEZZA, Cristovão; CASTRO, Gilberto de (Org.). Diálogos com Bakhtin. 4. ed. Curitiba: Editora da UFPR, 2007. p. 97-108.

JOUVE, Vincent. A leitura. São Paulo: Editora da UNESP, 2002.

KRAMER, Sonia (Org.) Didática da linguagem: ensinar a ensinar ou ler e escrever? Campinas, SP: Papirus, 2002.

LAJOLO, Marisa. Do mundo da Leitura para a leitura do mundo. 2. ed. São Paulo: Ática, 1994. 


\section{Tertulia literari a : construyendo caminos para la formación literaria del maestro alfabetizador en la universidad}

\section{Resumen}

Este artículo presenta reflexiones sobre la educación literaria de los maestros de escuelas públicas que actúan en la educación infantil y en la escuela primaria, como condición de participantes en un proyecto de extensión de la Universidade Federal de Minas Gerais, Brasil. Iniciado en el año 2009, el proyecto "Tertúlia Literária: quem lê também tem muito a dizer" (Tertulia literaria: quien lee también tiene mucho que decir) concibe la práctica de la lectura como una actividad propicia para el establecimiento de las relaciones interpersonales, y para que esto suceda, mantiene reuniones mensuales con el fin de socializar lecturas realizadas cada mes por los profesores e invitados mediadores. En seis años consecutivos de reuniones y diversas actividades, sigue buscando resaltar la lectura literaria como una de las lecturas que deben formar parte de la vida y por lo tanto de la trayectoria de formación docente. La experiencia del Proyecto busca romper con modelos de formación que dificultan e incluso alejan a los lectores de los libros de literatura. Este texto tiene como objetivo discutir y reflexionar acerca de aspectos de la lectura literaria que el proyecto ha revelado, en el contexto de formación de la Universidad.

\section{Literary Salon: building paths to literary training of literacy teachers at the university}

\section{Abstract}

This article reflects on the literary training of a group of public school teachers who work in childhood education and the early primary school years, and who participated in extension project at UFMG. The project "Tertúlia Literária: quem lê também tem muito a dizer" (Literary Talk: the one who reads also has a lot to say), which was has begun in 2009, views the practice of reading as an activity that supports the establishment of intersubjective relationships and contributes to achieving this by encouraging monthly gatherings to create socialization opportunities around readings by teachers and invited guests. After six consecutive years of gatherings and various activities, it was identified that literature remains one of the reading formats that should be part of life and, consequently, of teacher training. Accumulated experience brings together elements about literary reading in the context of the Project, which seeks to break with the training models that make difficult or even diminish the desired connection between readers and literature books. This paper seeks to discuss and question the aspects of literary reading raised by the Project, within the training context of the University. 

dores na universidade

Palabras claves: Literatura. Lectura literaria. Formación del professorado.
Keywords: Literature. Reading. Education Teacher.

\section{Celia Abicalil Belmiro}

E-mail: celiaabicalil@gmail.com

\section{Maria Zélia Versiani Machado}

E-mail: zelia.versiani@gmail.com

\section{Mônica Correia Baptista}

E-mail: monicacb.ufmg@gmail.com

Enviado em: 29/8/2014 Aprovado em: 11/11/2014 